\title{
ARTICLE OPEN Effect of ionic composition on thermal properties of energetic ionic liquids
}

\author{
Chihyun Park ${ }^{1}$, Minsu Han ${ }^{1}$, Jinbo Kim , Woojae Lee ${ }^{1}$ and Eunkyoung Kim (iD)
}

A model to predict the effect of ionic composition on the thermal properties of energetic ionic liquids was developed by quantitative structure-property relationship modeling, which predicted the detonation velocity, pressure, and melting temperature of energetic ionic liquids. A hybrid approach was used to determine the optimal subset of descriptors by combining regression with the genetic algorithm as an optimization method. The model showed the high accuracy, reaching a correlation factor of $R^{2}$ as 0.71 , 0.73 and 0.68 for the correlation between the calculated detonation velocity, pressure and melting temperature against reported values. It was validated extensively and compared to the Kamlet-Jacobs equation. The effect of ion composition on the thermal properties of energetic ionic liquids could be quantitatively analyzed through the developed model, to give an insight for the design of new energetic ionic liquids.

npj Computational Materials (2018)4:26; doi:10.1038/s41524-018-0082-y

\section{INTRODUCTION}

lonic liquids (ILs) have drawn considerate interest due to their unique properties such as high stability, high ionic conductivity, low toxicity, and structural diversity. Thus ILs are widely applied in various fields, including electrochemical devices, synthesis, energy harvesters, bioengineering, and material science. ${ }^{1-4}$ Above all, their low vapor pressure and hydrophobic nature are advantageous for the storage of energetically unstable materials. Recently, several high energy density ILs and hypergolic ILs were introduced as potential propellants. ${ }^{5-7}$ The ionic bonding between the cation and anion in ILs could be tailor-made, to give high energy density, by simple ion exchange and this process is easier as compared to traditional electrically neutral materials. Therefore, each of these cations and anions are "building blocks" for high-energy ionic liquids. ${ }^{8,9}$ In this context, the ionic liquids could be designed as stable non-toxic alternatives and replace traditionally toxic and highly unstable energetic neutral materials such as TNT $(2,4,6-$ trinitrotoluene) and hydrazine. ${ }^{10-14}$

Despite these advantages, the choices for ion paring between anions and cations are limited in the development of new EILs when a new cation or anion is necessary. ${ }^{15-17}$ This could be attributed to that there are very few selection rules for pairing ions with their counter ions. The lattice energy consideration of ion pairs is one of the selection rules, however, the lattice energy greatly affects the heat of formation and the density of the energetic material. Therefore, it is difficult to select counter ions until the material is actually synthesized. Although it is possible to estimate the lattice energy and density, ${ }^{18}$ this estimation inevitably involves simulation errors. Therefore, the error in the predicted values is amplified, yielding calculated values with a poor accuracy.

To predict the thermal and energetic properties of ionic materials, the Kamlet-Jacobs equation ${ }^{19}$ or a state equation- based program such as Explo $5^{20}$ or Cheetha ${ }^{21}$ have been used. However, these existing methods require information on the heat of formation $\left(\Delta \mathbf{H}_{\mathbf{f}}\right)$ and density $(\rho)$ of target structures, which require time staking computation and synthesis of target material, respectively. Thus, there is a strong need for a reliable tool to predict target properties in a fast and simple manner before synthesizing the material.

Since the quantitative structure-property relationship (QSPR) method is based on the conjecture that differences in the properties of chemicals is determined by differences in their chemical structures, ${ }^{22}$ it has been generated a simulation model with which to predict the toxicity ${ }^{23}$ and decomposition temperature $\left(T_{\mathrm{d}}\right)$ of some ILs ${ }^{24}$ without requiring their synthesis.

Therefore, we explored a QSPR model that predicts the thermal characteristics of ElLs using simple structural information on cation and anion pair without using $\Delta \boldsymbol{H}_{\mathrm{f}}$ and $\boldsymbol{\rho}$. Although there is a report on the QSPR model to predict the thermal decomposition temperature $\left(\boldsymbol{T}_{\mathrm{d}}\right)$ of imidazolium ILs, ${ }^{24}$ there has been no report on the energetic properties for a wide range of energetic ionic liquids including azoles and acyclic energetic salts. Herein, we report a QSPR model for the prediction of detonation characteristics for ionic liquids, through multiple linear regression derived from over 300 energetic ionic liquids.

\section{RESULTS AND DISCUSSION}

Building database

The number of structural descriptors used for QSPR modelling ${ }^{25,26}$ was 12 , including the molar weight (Mw), molar weight difference between an ion pair $\left(\mathbf{M}_{\mathbf{d}}\right)$, the atomic number of positively charged carbon $\left(\mathbf{C}^{+}\right)$, nitrogen $\left(\mathbf{N}^{+}\right)$, and oxygen $\left(\mathbf{O}^{+}\right)$, and negatively charged carbon $\left(\mathbf{C}^{-}\right)$, nitrogen $\left(\mathbf{N}^{-}\right)$, oxygen $\left(\mathbf{O}^{-}\right)$, and chlorine $\left(\mathbf{C l}^{-}\right)$, the number of each atoms in ions, the square sum

\footnotetext{
${ }^{1}$ Department of Chemical and Biomolecular Engineering, Yonsei University, 50 Yonsei-ro, Seodaemun-gu, Seoul 03722, Korea Correspondence: Eunkyoung Kim (eunkim@yonsei.ac.kr)
}

Received: 13 January 2018 Revised: 13 April 2018 Accepted: 19 April 2018

Published online: 16 May 2018 
of the ionic charge (qt), the modified oxygen balance (mOB), the number of chemical bonds including single and multiple bonds (nBT), the number of multiple bonds (nBM), the number of atoms in a ring structure (nRA), and the length of conjugation (nCG). The ionic liquids were composed of different cations and anions, and their descriptors were calculated as a sum of cations and anions to develop simple and convenient models without considering more sophisticated and complex molecular descriptors. The square sum of the ionic charge (qt) was selected to consider the ionic interaction between cations and anions. The $\mathbf{M w}, \mathbf{M}_{\mathbf{d}}$, and the atomic composition descriptors (a-d) were calculated by employing ChemDraw Ultra 8.0. The atomic composition descriptors were calculated by dividing the number of each atom against total number of atoms. The $\mathbf{m O B}$ was calculated using Eq. 1.

$$
\mathbf{m O B}=-\mathbf{O B}[\%] / 100=16 / \mathbf{M w} \times(2 \boldsymbol{a}+\boldsymbol{b} / 2-\boldsymbol{c})
$$

Other descriptors (qt, $\mathbf{n B T}, \mathbf{n B M}, \mathbf{n R A}$, and $\mathbf{n C G}$ ) were calculated from the molecular structure of EILs. The descriptor values for all compounds in this study are summarized in Supplementary Table S1. Using the calculated descriptor values, the optimal subset of descriptors that contribute significantly to the reported detonation properties were selected by the correlation of each descriptor data to the detonation properties of the corresponding materials (Supplementary Figure S1). The least mean square algorithm (LS) and genetic algorithm (GA) were applied to the regression method as described below. Among the 12 structural descriptors, 10 were finally selected: $\mathbf{M w}$, the atomic composition of atoms (a d), nBT, nBM, qt, mOB, and $\mathbf{n R A}$. While selecting descriptors for modelling, we used primary descriptors that can be easily obtained simply from their molecular structures without the descriptors that had to be obtained experimentally because the ultimate goal of this research is to find a QSPR model that is useful for estimating the detonation properties based on the structure of the ionic liquids, which allows the fast and easy calculation of the detonation properties of a target molecule.

Model development based on multiple linear regression (MLR) First, a hybrid approach was used to determine the optimal subset of descriptors by combining regression with the least-mean square algorithm $(\mathbf{L S})^{27}$ or the genetic algorithm $(\mathbf{G A})^{28}$ as an optimization method. The Multiple linear regression (MLR) analysis (Eq. 2) were used to develop a QSPR model that accurately features relationships between ionic structures and the detonation velocity of ElLs.

$$
\begin{gathered}
D v_{\mathrm{MLR}}=C_{0}+C_{1} \mathrm{Mw}+C_{2} \mathrm{nBT}+C_{3} \mathrm{nBM}+C_{4} q_{t} \\
+C_{5} \mathrm{mOB}+C_{6} \mathrm{nRA}+C_{7} \mathrm{C}^{+}+C_{8} \mathrm{~N}^{+}+C_{9} C_{\mathrm{cat}} \\
+C_{10} \mathrm{H}_{\mathrm{cat}}+C_{11} \mathrm{O}_{\mathrm{cat}}+C_{12} \mathrm{~N}_{\mathrm{cat}}+C_{13} \mathrm{C}^{-}+C_{14} \mathrm{~N}^{-} \\
+\mathrm{C}_{15} \mathrm{O}^{-}+C_{16} \mathrm{C}_{\mathrm{ani}}+\mathrm{C}_{17} \mathrm{H}_{\mathrm{ani}}+C_{18} \mathrm{O}_{\mathrm{ani}} \\
+C_{19} \mathrm{~N}_{\mathrm{ani}}+C_{20} \mathrm{Cl}_{\mathrm{ani}}
\end{gathered}
$$

The detonation pressure was expressed in the same form as above.

$$
\begin{gathered}
D p_{\mathrm{MLR}}=C_{0}+C_{1} \mathrm{Mw}+C_{2} \mathrm{nBT}+C_{3} \mathrm{nBM}+C_{4} q_{t} \\
+C_{5} \mathrm{mOB}+C_{6} \mathrm{nRA}+C_{7} \mathrm{C}^{+}+C_{8} \mathrm{~N}^{+}+C_{9} \mathrm{C}_{\mathrm{cat}} \\
+C_{10} \mathrm{H}_{\mathrm{cat}}+C_{11} \mathrm{O}_{\mathrm{cat}}+C_{12} \mathrm{~N}_{\mathrm{cat}}+C_{13} \mathrm{C}^{-} \\
+C_{14} \mathrm{~N}^{-}+C_{15} \mathrm{O}^{-}+C_{16} \mathrm{C}_{\mathrm{ani}}+C_{17} \mathrm{H}_{\mathrm{ani}} \\
+C_{18} \mathrm{O}_{\text {ani }}+C_{19} \mathrm{~N}_{\text {ani }}+C_{20} \mathrm{Cl}_{\mathrm{ani}}
\end{gathered}
$$

where $C_{i}(i=0-20)$ are the different fitting parameters for each formula. The MLR method, which is the most basic expressions used in establishing QSPR-based expression, ${ }^{29}$ is a sophisticated hybrid approach in which either LS or GA is applied as a powerful optimization method, creating a popular statistical method for variable selection. Both $\mathbf{L S}$ and $\mathbf{G A}$ were examined to determine the optimal subset of descriptors that accurately represented the relationships between ionic structures and the detonation properties of ILs.

The fitting of each model to the reported detonation properties was conjectured from the root mean-square error of crossvalidation (RMSECV). The RMSECV for Dv prediction with the QSPR model developed from LS-MLR (QML) and GA-MLR (QMG) were 911.4 and 416.2, respectively, while those for $D p$ with the QML and QMG were 4.70 and 3.16, respectively. The RMSECV for $D v$ and $D p$ prediction with the QMG model were obviously larger than for other models. Therefore, the QMG models were selected for further consideration. External validation was performed by dividing the 316 data set randomly into a training set and an external test set, similar to the methods in previous report. ${ }^{24}$ The training set ( $250 \mathrm{ILs}, 80 \%$ of the data set) was used for descriptor selection and model development and the test set (67 ILs, 20\% of the data set) was used for model validation.

Calculation of detonation properties by Kamlet-Jacobs (KJ) equations

The Kamlet-Jacobs equations ${ }^{19}$ (Eq. 4, 5), which are commonly used to predict the detonation properties of energetic materials, were used as a reference to estimate the QSPR model's validity.

$D v_{K J}=1010\left(N \bar{M}^{0.5} Q^{0.5}\right)^{0.5}(1+1.30 \rho)$

$D p_{K J}=1.558 \rho^{2} N \bar{M}^{0.5} Q^{0.5}$

where $D v_{K J}$ was the detonation velocity $(\mathrm{m} / \mathrm{s}), D p_{K J}$ was the detonation pressure (GPa), $\mathrm{N}$ was the molar amount of gas produced from each explosive material, $\bar{M}$ was the average molecular weight of the gas produced from each explosive material, and $\mathrm{Q}$ is the detonation heat in $\mathrm{cal} / \mathrm{g}$. These three values were calculated from the chemical formulae. $\Delta \mathbf{H}_{\mathbf{f}}$ and $\boldsymbol{\rho}$ for the calculation of $\mathrm{KJ}$ were obtained from the reported values (see references in Supplementary Table S1).

Applicability of the QSPR model

QSPR has been known as a powerful modelling method, but it is important to ensure accuracy by limiting its coverage to specific chemicals. ${ }^{30,31}$ The databases used to establish the model were all ionic liquids; non-ionic materials were not included. Since the electrical properties of the ion were taken into account when calculating the model, it is difficult to apply this to nonionic materials. In addition, most of the materials considered were organic, thus $\mathrm{C}, \mathrm{H}, \mathrm{O}$, and $\mathrm{N}$ were the main components. The 
quantities of these four atoms was used as an important descriptor and they cannot be applied to completely different inorganic chemicals. The applicability domain (AD) of this model can be precisely defined using the standardization approach ${ }^{32}$, which were performed by analysing all dataset. The applicable area calculated by standardization approach was $98.7 \%$. (Supplementary Figure S2)

The collected data of 316 substances (Supplementary Table S1) for the creation of the QSPR model were based on energetic ionic liquids including ammonium, guanidinium, and azolium salts, of which anions varied from simple halide and borohydride to azolium or multi-cyclic azide and amide. These reported EILs were synthesized substances; thus the data were more reliable than that for artificial materials created via calculations. The wide range of structural variety could generate a more accurate and credible model than the model based on a structurally similar group.

The energetic properties of those collected molecules were correlated with several parameters that are generally used as descriptors in quantitative structural-property analysis. ${ }^{25,26}$ As shown in Supplementary Figures S1 and S3, the detonation velocity of the 316 molecules correlated poorly with the number of atoms ( $\mathrm{C}, \mathrm{H}, \mathrm{O}$, and $\mathrm{N}$ ), and melting points (Tm). However, they were linearly correlated to the density $(\boldsymbol{\rho})$ and oxygen balance (OB). The respective correlation factors $\left(R^{2}\right)$ for $\rho$ and OB were 0.61 and 0.47 , indicating that $\boldsymbol{\rho}$ was better fitted to the detonation properties, possibly because the actual density played an important role in determining the explosive characteristics.

The contribution from the structural parameters on the detonation velocity (and pressure) was considered in the QSPR model in this study, using primary structural factors such as the molar weight $(\mathbf{M w})$, the atomic number of positively charged carbon $\left(\mathbf{C}^{+}\right)$and nitrogen $\left(\mathbf{N}^{+}\right)$, and negatively charged carbon $\left(\mathbf{C}^{-}\right)$, nitrogen $\left(\mathbf{N}^{-}\right)$, and oxygen $\left(\mathbf{O}^{-}\right)$, the number of each atoms in ions, the number of single (nBT) and multiple bonds (nBM), the modified oxygen balance (mOB), the square sum of the ionic charge (qt), and the number of atoms in a ring structure (nRA), etc. (see the experimental part). While selecting descriptors for modelling, we used primary descriptors that can be easily obtained by their structures, without descriptors that had to be obtained experimentally; this ensured the rapid speed of calculations and created a model based on descriptors that did not require experimental data or multiple additional simulations.

Since ionic liquids are composed of different cations and anions, qt was selected to account for ionic interactions between cations and anions. The structural descriptor values for each material were obtained from their chemical structure, as summarized in Supplementary Table S1. The most statistically effective descriptors for the detonation properties of ionic liquids were selected through least mean square multiple linear regression and the calculated values were compared with those obtained from the Kamlet-Jacobs equations (Eq. 4, 5) ${ }^{19}$, which are commonly used to predict the properties of explosives.

Creation of a QSPR Model for EILs

A QSPR model that can predict the thermal properties (detonation velocity, detonation pressure and melting point) of ionic liquids was developed from their basic chemical structures, using the multiple linear regressions (Eq. 2, 3). The multiple linear regressions have been widely used to establish QSPR-based expressions such as models that can predict the decomposition temperature or viscosity of ionic liquids. ${ }^{24,29}$ Among the collected data for 316 materials, 250 were randomly selected for use as the training set, and the remaining 67 were used as the test set. The established QML and QMG models for the calculation of the detonation velocity (Dv) of EILs, through the least-mean square algorithm (LS) and genetic algorithm (GA), respectively, are represented as Eq. 6, 7 :

$$
\begin{aligned}
& D v_{\mathbf{Q M L}}=-1.43 \mathrm{Mw}+31.03 \mathrm{nBT}-95.13 \mathrm{nBM}-2320.30 \mathrm{q}_{\mathrm{t}} \\
&- 12.95 \mathrm{mOB}+15.18 \mathrm{nRA}+6833.90 \mathrm{C}^{+} \\
&+ 7193.62 \mathrm{~N}^{+}-170.27 \mathrm{C}_{\mathrm{cat}}-51.89 \mathrm{H}_{\mathrm{cat}}+72.10 \mathrm{O}_{\mathrm{cat}} \\
&+ 78.37 \mathrm{~N}_{\mathrm{cat}}+6653.46 \mathrm{C}^{-}+6846.14 \mathrm{~N}^{-} \\
&+6910.89 \mathrm{O}^{-}-73.07 \mathrm{C}_{\mathrm{ani}}-5.92 \mathrm{H}_{\mathrm{ani}} \\
&+11.64 \mathrm{O}_{\mathrm{ani}}+32.20 \mathrm{~N}_{\mathrm{ani}}-372.30 \mathrm{Cl} \mathrm{ani} \\
& D v_{\mathrm{QMG}}= 6660.55-1.70 \mathrm{Mw}+33.50 \mathrm{nBT}-95.38 \mathrm{nBM} \\
&-616.42 \mathrm{q}_{\mathrm{t}}-12.18 \mathrm{mOB}+15.00 \mathrm{nRA}+1811.85 \mathrm{C}^{+} \\
&+2198.41 \mathrm{~N}^{+}-177.84 \mathrm{C}_{\mathrm{cat}}-55.97 \mathrm{H}_{\mathrm{cat}}+82.50 \mathrm{O}_{\mathrm{cat}} \\
&+
\end{aligned}
$$

Similarly, the QML and QMG models for the detonation pressure $(D p)$ were established as follows:

$$
\begin{gathered}
D p_{\mathrm{QML}}=0.23 \mathrm{nBT}-1.06 \mathrm{nBM}-9.87 \mathrm{q}_{\mathrm{t}}-0.13 \mathrm{mOB}-0.02 \mathrm{nRA} \\
+28.62 \mathrm{C}^{+}+31.12 \mathrm{~N}^{+}-0.53 \mathrm{C}_{\mathrm{cat}}-0.92 \mathrm{H}_{\mathrm{cat}}+1.03 \mathrm{O}_{\mathrm{cat}} \\
+0.43 \mathrm{~N}_{\mathrm{cat}}+24.71 \mathrm{C}^{-}+25.92 \mathrm{~N}^{-}+27.01 \mathrm{O}^{-}-0.29 \mathrm{C}_{\mathrm{ani}} \\
-0.75 \mathrm{H}_{\mathrm{ani}}+0.34 \mathrm{O}_{\mathrm{ani}}+0.59 \mathrm{~N}_{\mathrm{ani}}+0.10 \mathrm{Cl}_{\mathrm{ani}}
\end{gathered}
$$

$$
\begin{gathered}
D p_{\mathrm{QMG}}=23.49+0.19 \mathrm{nBT}-0.84 \mathrm{nBM}-1.82 \mathrm{q}_{\mathrm{t}}-0.06 \mathrm{mOB} \\
+0.05 \mathrm{nRA}+5.28 \mathrm{C}^{+}+9.61 \mathrm{~N}^{+}-1.41 \mathrm{C}_{\mathrm{cat}}-0.73 \mathrm{H}_{\mathrm{cat}} \\
+1.75 \mathrm{O}_{\mathrm{cat}}+0.59 \mathrm{~N}_{\mathrm{cat}}+0.62 \mathrm{C}^{-}+2.86 \mathrm{~N}^{-}+4.56 \mathrm{O}^{-} \\
-0.99 \mathrm{C}_{\mathrm{ani}}-0.62 \mathrm{H}_{\mathrm{ani}}+0.97 \mathrm{O}_{\mathrm{ani}}+0.68 \mathrm{~N}_{\mathrm{ani}}+0.94 \mathrm{Cl}_{\mathrm{ani}}
\end{gathered}
$$

The calculated data for each method are compared with the reported values in the literature, in Fig. 1, in which black dots indicate the training set and red dots indicate the test set data. As can be seen in Fig. 1a, the calculated data obtained from the $\mathrm{K}-\mathrm{J}$ equation did not match the reported values, indicating that they had a large error for estimating the detonation speed of ionic materials. The $R^{2}$ value was -3.63 , which meant that the $\mathrm{K}-\mathrm{J}$ equation cannot function as a design rule. 
(a)

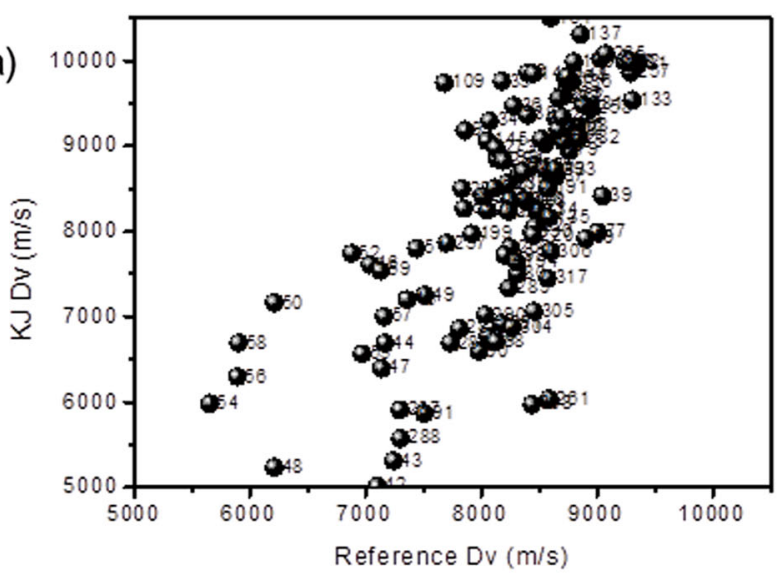

(b)

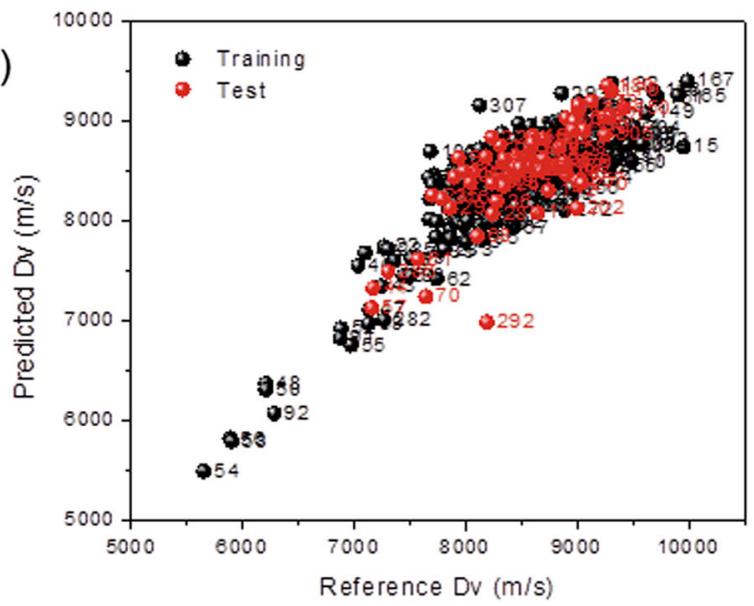

(c)

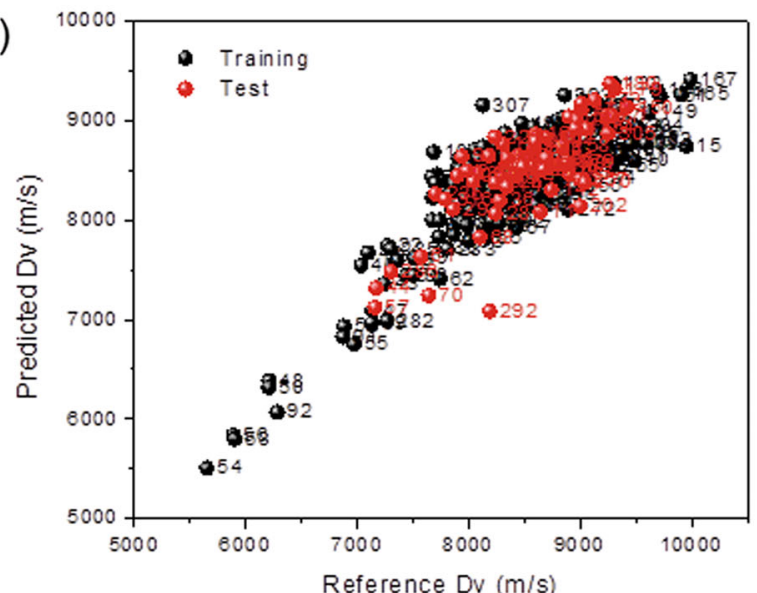

(d)

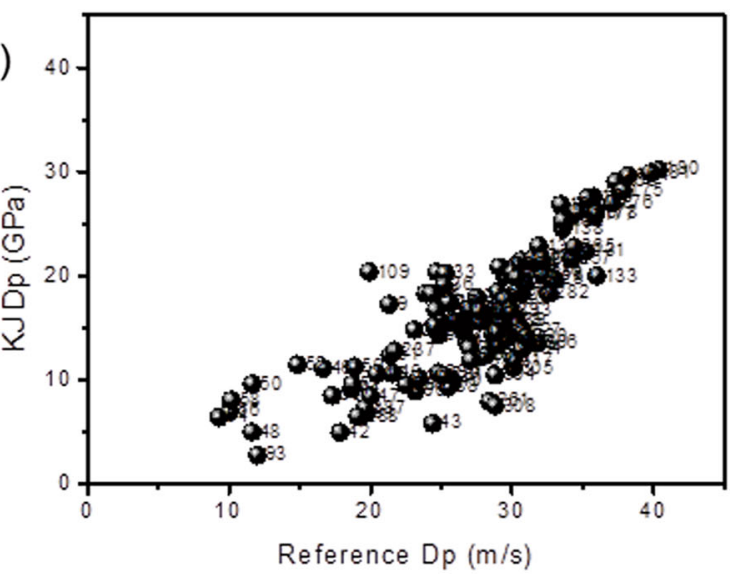

(e)

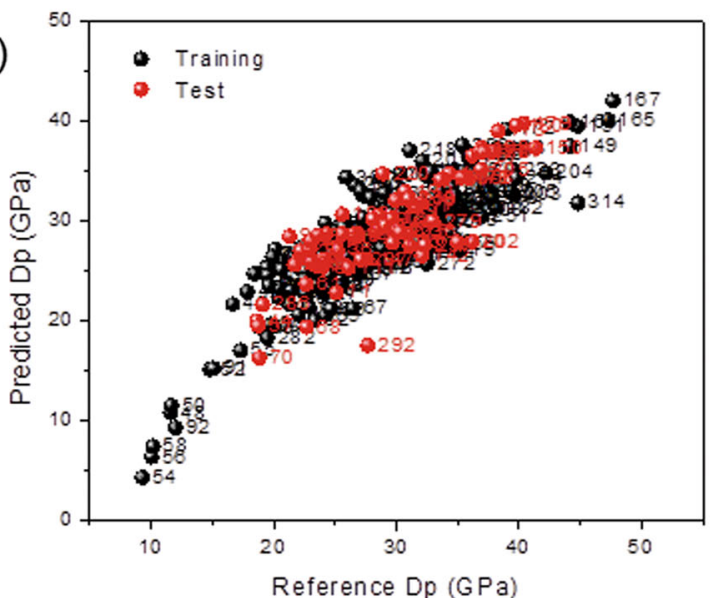

(f)

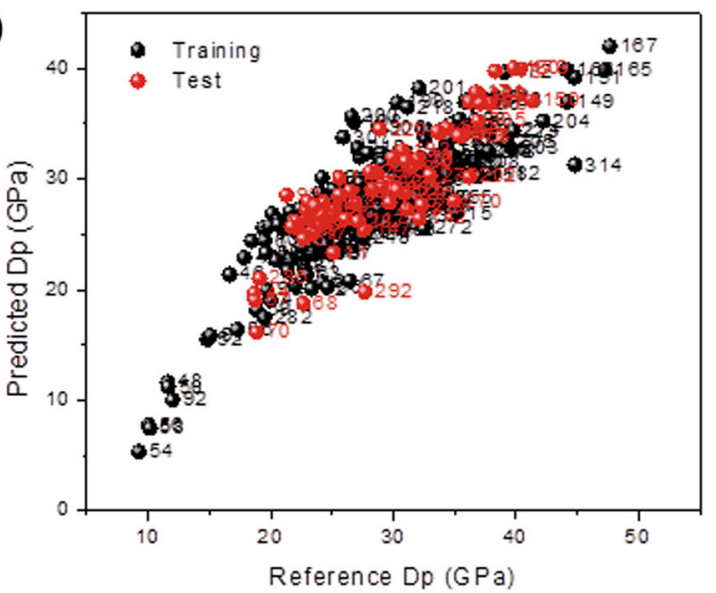

Fig. 1 Comparison of predicted detonation velocity (Dv) by (a) the Kamlet-Jacobs equation, (b) QML, and (c) QMG of ionic liquids against reference Dv. Comparison of calculated detonation pressure $(D p)$ by (d) the Kamlet-Jacobs equation, (e) QML and (f) QMG of ionic liquids against reference $D p$

Figure $1 \mathrm{~b}$, and $\mathrm{c}$ show the data variance of the QML and QMG models, respectively, for the calculated detonation velocity against the reported values. These models reveal relatively high accuracy compared to the K-J equation. Interestingly, the QMG model matched the reported $D v$ better than QML. The correlation factors $\left(R^{2}\right)$, validation set $\left(\mathrm{q}_{\mathrm{ext}}{ }^{2}\right)$, and slope of regression $(\mathrm{k})$ for the QMG were $0.71,0.58$, and 0.73 , which are higher than that from the QML method, as compared in Table 1.
Similarly, the calculated data by the QMG model matched well with the reported detonation pressure $(D p)$ (Supplementary Figure S4b). As shown in Fig. 1d, the data from the K-J equation were outside the linear region when correlated with the reported values of $D p$ for the ionic material. The $R^{2}$ value was -3.41 , thus, the $\mathrm{K}-\mathrm{J}$ equation did not function as a design rule for the detonation pressure either. In contrast, the $R^{2}$ values of the QSPR-based models were 0.70 and 0.71 for the QML, and QMG models, respectively. Therefore, it become possible to predict the 
energetic properties of ionic materials with high accuracy when using these models. In particular, the QMG model showed the highest $R^{2}$ among the models. Figure 2 compares the histogram of appearance for the detonation velocity and the detonation pressure of EILs from the QML and QMG models. The QMG model showed a narrower $\mathbf{N}_{\mathbf{P}}$, suggesting that the QMG model provided calculated data with higher accuracy for both the detonation velocity and the detonation pressure.

Even though all descriptors in this study were obtained from the structure of ElLs rather than experiments, the above QSPR models showed much higher accuracy than the K-J equations, which require the density and heat of formation. It is remarkable that the accuracy of the QMG model was high; this suggests that the detonation velocity and pressure are linearly correlated to the combination of selected descriptors.

\section{Descriptor analysis}

Let us consider the contribution of each descriptor in Eq. 7. Scale and proportion of each descriptor are summarized in Table 2. Descriptors with the largest value in each model are written in bold, and the proportion of the scale converted by multiplying the standard deviation of each descriptor is shown in parentheses. Major descriptors having a high contribution to the thermal and energetic properties of ElLs are highlighted in yellow. Among the descriptors, the contribution of the charged atoms $\left(\mathbf{C}^{+}, \mathbf{N}^{+}, \mathbf{C}^{-}\right.$,

\begin{tabular}{|llll|}
\hline $\begin{array}{l}\text { Table 1. The correlation factors }\left(\mathrm{R}^{2}\right) \text {, validation set }\left(\mathrm{q}_{\mathrm{ext}}{ }^{2}\right) \text {, and slope of } \\
\text { regression }(\mathrm{k}) \text { for each models }\end{array}$ & \multicolumn{2}{l}{${ }^{2}$} & $k$ \\
\hline Dv & $R^{2}$ & - & 1.44 \\
\hline K-J & -3.63 & 0.56 & 0.73 \\
QML & 0.70 & 0.58 & 0.73 \\
QMG & 0.71 & $q_{\mathrm{ext}}^{2}$ & $k$ \\
Dp & $R^{2}$ & - & 0.66 \\
K-J & -3.41 & 0.70 & 0.75 \\
QML & 0.73 & 0.75 & 0.75 \\
QMG & 0.73 & $q_{\mathrm{ext}}^{2}$ & $k$ \\
QMGAZ & $R^{2}$ & 0.68 & 0.75 \\
QMGAZ - Dv & 0.75 & 0.79 & 0.74 \\
QMGAZ - Dp & 0.75 &
\end{tabular}

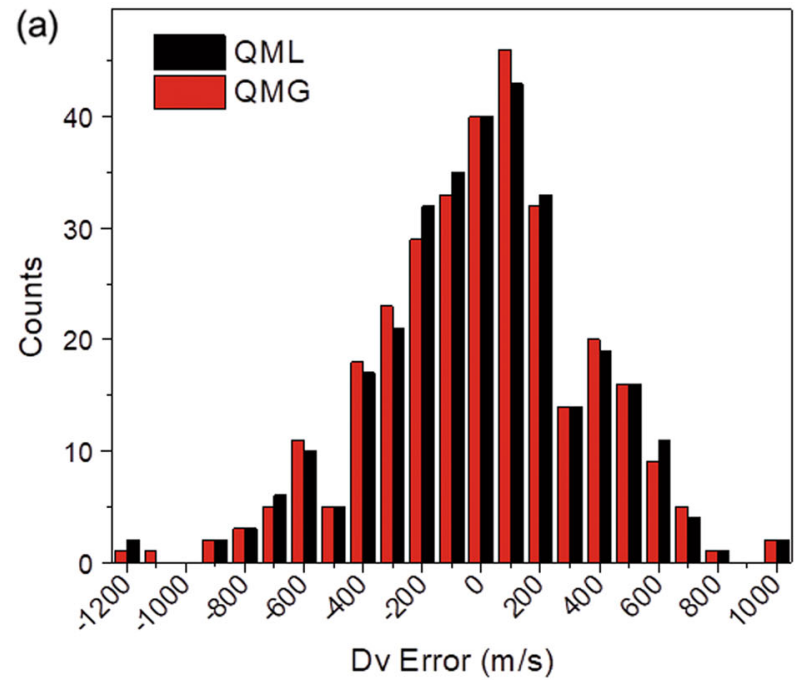

$\mathbf{N}^{-}$, and $\mathbf{O}^{-}$) to the calculated $D v$ was much larger than the rest of the descriptors. This could be attributed to that the lattice energy increases as the interaction between highly charged ions is increased, and the heat of the formation of ionic liquids decreases as the lattice energy increases. ${ }^{18}$ In particular, EILs consisting of a pair of cations with $\mathrm{N}^{+}$and an anion with $\mathrm{O}^{-}$are predicted to have a high detonation velocity, which indeed shows a high detonation velocity reaching $9130 \mathrm{~m} / \mathrm{s}$ as shown in the $\mathrm{H}_{3}$ tta derivatives (173). ${ }^{33}$

It has been known that the number of atoms increased, the heat formation of ElLs could be increased, and thus Dv was expected to increase. ${ }^{19}$ But as summarized in Table 2, the increase

Table 2. Descriptors of QMG models. (Parentheses; percentage of reduced contribution calculated by multiplying descriptor and standard deviation. Bold; descriptors with noticable value in each model.)

\begin{tabular}{lll}
\hline Descriptors & $D v$ & $D p$ \\
\hline $\mathrm{Mw}$ & $-2(3)$ & $0.00(1)$ \\
$\mathrm{nBT}$ & $33(5)$ & $0.19(7)$ \\
$\mathrm{nBM}$ & $-95(4)$ & $-0.84(8)$ \\
$\mathrm{qt}$ & $-616(12)$ & $-\mathbf{1 . 8 2}(\mathbf{8})$ \\
$\mathrm{mOB}$ & $-12(4)$ & $-0.06(5)$ \\
$\mathrm{nRA}$ & $15(1)$ & $0.05(1)$ \\
$\mathrm{C}+$ & $\mathbf{1 8 1 2 ( 8 )}$ & $\mathbf{5 . 2 8}(\mathbf{5})$ \\
$\mathrm{N}+$ & $\mathbf{2 1 9 8 ( 6 )}$ & $\mathbf{9 . 6 1 ( 6 )}$ \\
$\mathrm{C}$ & $-178(4)$ & $-1.41(7)$ \\
$\mathrm{H}$ & $-56(1)$ & $-0.73(4)$ \\
$\mathrm{O}$ & $82(1)$ & $1.75(3)$ \\
$\mathrm{N}$ & $83(2)$ & $0.59(4)$ \\
$\mathrm{C}-$ & $\mathbf{1 5 3 0 ( 1 4 )}$ & $0.62(1)$ \\
$\mathrm{N}-$ & $\mathbf{1 7 3 7 ( 1 5 )}$ & $\mathbf{2 . 8 6 ( 5 )}$ \\
$\mathrm{O}-$ & $\mathbf{1 8 0 5 ( 1 4 )}$ & $\mathbf{4 . 5 6 ( 8 )}$ \\
$\mathrm{C}$ & $-80(2)$ & $-0.99(6)$ \\
$\mathrm{H}$ & $-8(0)$ & $-0.62(4)$ \\
$\mathrm{O}$ & $21(1)$ & $0.97(9)$ \\
$\mathrm{N}$ & $36(2)$ & $0.68(8)$ \\
$\mathrm{Cl}$ & $-334(1)$ & $0.94(0)$ \\
\hline
\end{tabular}

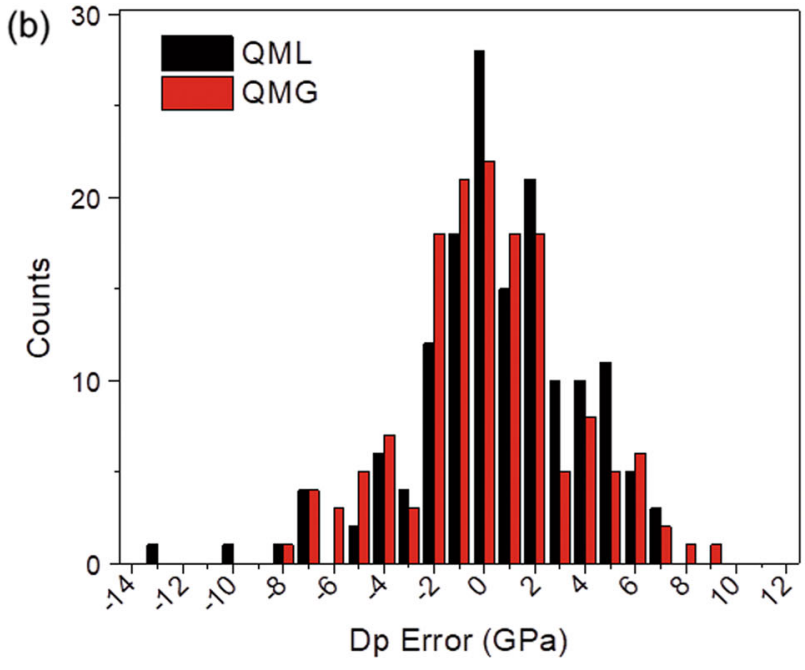

Fig. 2 Histogram of appearance for (a) the calculated $D v$ and (b) $D p$ by black (QML), and red (QMG) 
in molecular weight due to the increase in the number of carbon atoms adversely affects the detonation velocity, while the increase in oxygen and nitrogen number has a positive effect. lonic charge (qt) appears to have a negative effect, but it should be noted that the increase in charged atoms has a high positive impact, resulting in a multivalent ion having a higher detonation velocity. The oxygen balance (OB) and ring-forming atoms (nRA) also positively contributed to the calculated $D v$. With Eq. 7, it is expected that a material with a structure similar to a cyclic explosive such as RDX or HMX would also have a high detonation. An increase in the number of multiple bonds (nBM) of ElLs showed a detrimental effect on the detonation velocity; this could be attributed to the increase in molecular interactions through the $\pi-\pi$ interactions of multiple bonds. ${ }^{34}$

The detonation pressure also showed a tendency similar to the detonation velocity. In particular, the charged atom combination of $\mathrm{N}^{+}$and $\mathrm{O}^{-}$exhibits a high detonation pressure, confirming a detonation pressure of $38.28 \mathrm{GPa}$ of material 173; therefore, the detonation pressure is highly dependent on the oxidation that consumes oxygen atoms of EILs, particularly when it explodes. This observation was consistent with previous studies. ${ }^{35,36}$ In addition, the detonation pressure tended to increase as the number of ring-forming atoms (nRA) increased. Considering the above results, the most promising structure was finally assumed to be a ring structure that contains oxygen.

\section{Calculation of melting points of EILs}

The QSPR model of melting points of ElLs were developed by applying the genetic algorithm based on the following Eqn. 10, in the same way as detonation velocity and detonation pressure. A total of 89 data were used, of which 19 were used as test sets.

$$
\begin{gathered}
\mathrm{Tm}_{\mathrm{MLR}}=C_{0}+C_{1} \mathrm{Mw}+C_{2} \mathrm{nBT}+C_{3} \mathrm{nBM}+C_{4} q_{t} \\
+C_{5} \mathrm{mOB}+C_{6} \mathrm{nRA}+C_{7} \mathrm{C}^{+}+C_{8} \mathrm{~N}^{+}+C_{9} \mathrm{C}_{\mathrm{cat}} \\
+C_{10} \mathrm{H}_{\mathrm{cat}}+C_{11} \mathrm{O}_{\mathrm{cat}}+C_{12} \mathrm{~N}_{\mathrm{cat}}+C_{13} \mathrm{C}^{-}+C_{14} \mathrm{~N}^{-} \\
+C_{15} \mathrm{O}^{-}+C_{16} \mathrm{C}_{\mathrm{ani}}+C_{17} \mathrm{H}_{\mathrm{ani}}+C_{18} \mathrm{O}_{\mathrm{ani}} \\
+C_{19} \mathrm{~N}_{\mathrm{ani}}+C_{20} \mathrm{Cl}_{\mathrm{ani}}
\end{gathered}
$$

where $C_{i}(i=0-20)$. The population of the genetic algorithm was 200 , the crossover fraction was 0.8 , and the simulation was conducted until it reached $100,000^{\text {th }}$ generations. Equation 11 was the result of the QMG based equation of Tm (Fig. 3). The melting point showed a general tendency to be directly proportional to the molecular weight of the substance and the number of charged atoms.

$$
\begin{gathered}
T m_{\mathrm{QMG}}=155.95+0.32 \mathrm{Mw}-8.65 \mathrm{nBT}+11.33 \mathrm{nBM} \\
-8.57 q_{t}+0.41 \mathrm{mOB}+2.41 \mathrm{nRA}-78.6 \mathrm{C}^{+}+55.16 \mathrm{~N}^{+} \\
-28.43 \mathrm{C}_{\mathrm{cat}}+18.81 \mathrm{H}_{\mathrm{cat}}+20.35 \mathrm{O}_{\mathrm{cat}}+11.56 \mathrm{~N}_{\mathrm{cat}} \\
+89.17 \mathrm{C}^{-}+67.4 \mathrm{~N}^{-}+65.3 \mathrm{O}^{-}+7.7 \mathrm{C}_{\mathrm{ani}} \\
-9.69 \mathrm{H}_{\mathrm{ani}}-0.72 \mathrm{O}_{\mathrm{ani}}+13.36 \mathrm{~N}_{\mathrm{ani}}+46.75 \mathrm{Cl}_{\mathrm{ani}}
\end{gathered}
$$

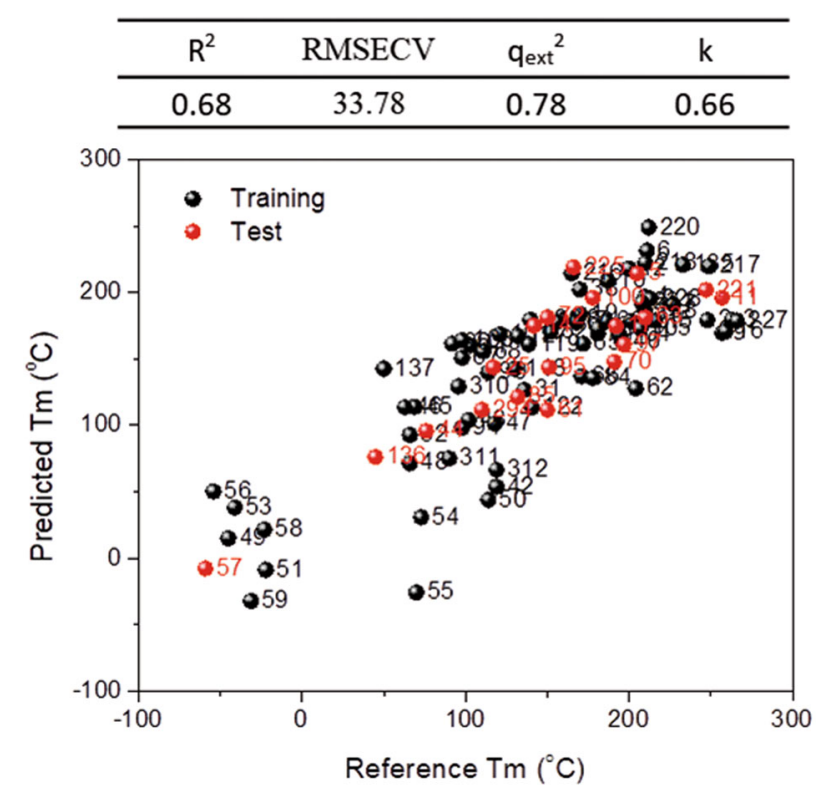

Fig. 3 Comparison of predicted melting temperature ( $\mathrm{Tm})$ by QMG. (Inset; validation factors of QMG model.)

$R^{2}$, RMSECV, $q_{\text {ext }}^{2}$ and $k$ values are $0.68,33.78,0.78$ and 0.66 as shown in inset of Fig. 3.

\section{Structural analysis}

The detonation velocity and pressure of EILs were highly dependent on both their cation and anion structure and their combination. Figure $4 a$ shows the detonation velocity values according to the cationic structure. The ElLs with small cations such as ammonium, hydroxylammonium, and hydrazinium structure showed Dvs larger than $9,300 \mathrm{~m} / \mathrm{s}$ (Fig. 4b) when combined with a large anion such as 1-nitro- $\mathrm{N}-(1-$ nitro- $1 \mathrm{H}-$ tetrazol-5-yl)-N-(1-oxide ion-tetrazol-5-yl)-1H-tetrazol-5-amine (A1 in cpd 167). This result well matches to the previous report in which the combination of a large anion and small cation could form high-density energetic compounds. ${ }^{37}$ Unlike most of the cations from ammonium to imidazolium ions, which were generally well distributed along the correlation line (dashed), the $D v$ values for hydrazinium groups (navy triangle) deviated from the correlation line (Fig. 4c). The deviation of hydrazinium from the correlation line could be attributed to the difference in the molecular interactions and/or the positive charge distribution on the cation. It has been reported that hydrazinium ions pertain lower electrostatic potential (ESP), which is a critical clue in intermolecular interactions. ${ }^{37}$ In particular, the deviation was larger when two hydrazinium ions were combined in an anion (cpd 307). Nonetheless, the hydrazinium group showed a higher $D v$ than guanidinium ions $(D v<9,200 \mathrm{~m} / \mathrm{s})$.

Among the azolinium ions, the tetrazolium group with a dinitroamide anion showed the highest $D v$ of $9,300 \mathrm{~m} / \mathrm{s}$. When anions were same, the tetrazolium showed higher $D v$ than triazolium groups. The imidazolium ions showed the lowest $D v$ among the cations in this study. This result could be attributed to the large contribution of the number of charged atoms on $D v$ (Eq. 7) and well matches to the previous report that the hypergolic properties of ILs become large in nitrogen-rich ILs. ${ }^{38}$ Almost the same ionic effects as those of $D v$ were observed for the detonation pressure $(D p)$ of ElLs (Fig. $4 \mathrm{~d}$ ), showing the order of $D p$ as hydrazinium $>$ tetrazolium $>$ ammonium $>$ guanidinium $>$ triazolium > imidazolium. 

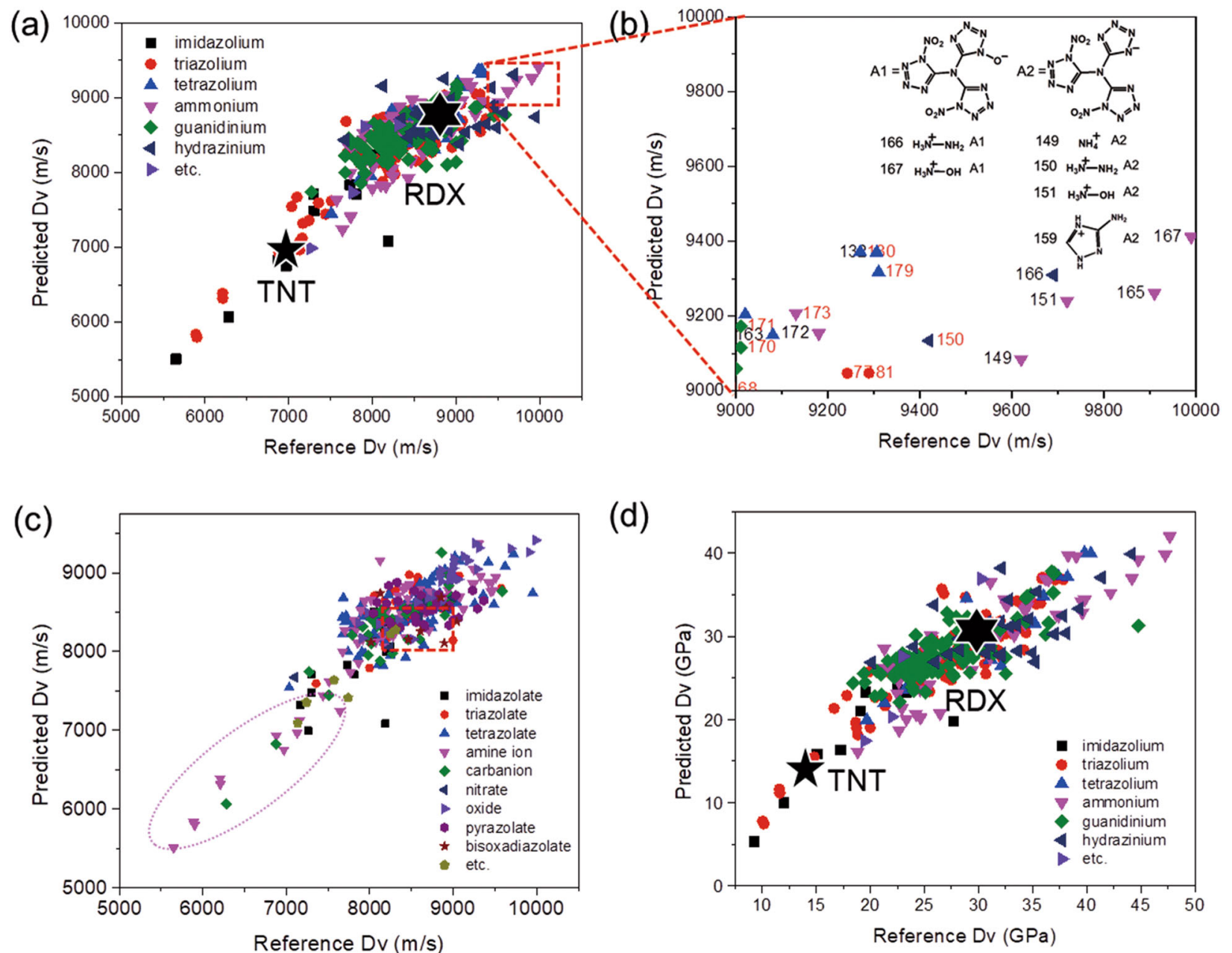

(d)

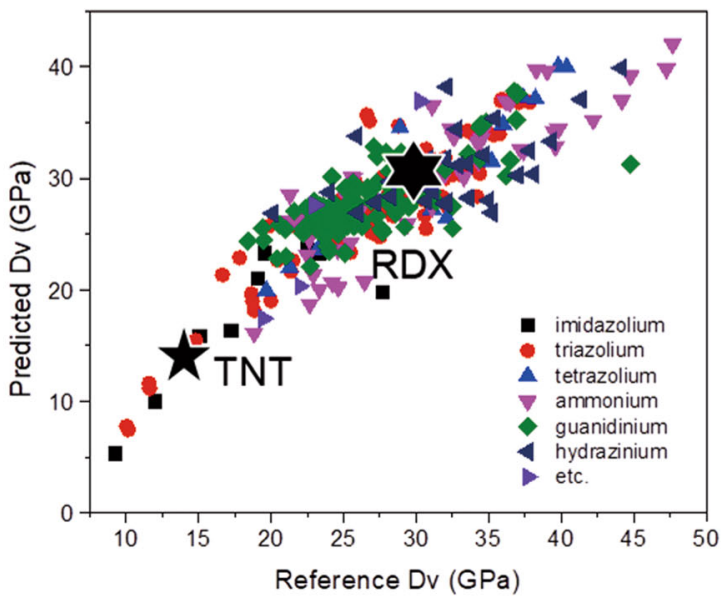

Fig. 4 a Structural analysis on cationic group of ionic liquids for detonation velocity. Black (imidazolium), red (triazolium), blue (tetrazolium), magenta (ammonium), green (guanidium), navy (hydrazinium), and pupple (others). b The ElLs having high $D v(>9000 \mathrm{~m} / \mathrm{s}$ ) in red box of (a). c Structural analysis on anionic group of ionic liquids for detonation velocity. Black (imidazolate), red (triazolate), blue (tetrazolate), magenta (amine ion), green (carbanion), navy (nitrate), wine (pyrazolate), brown (bisoxadiazolate), and dark yellow (others). d Structural analysis of cationic ionic liquids for detonation pressure calculated from Eq. 9. Black (imidazolium), red (triazolium), blue (tetrazolium), magenta (ammonium), green (guanidium), navy (hydrazinium), and pupple (others)

Table 3 summarizes the average detonation velocity of each structure. The detonation property was also established according to anion structure (Fig. 4d and Supplementary Figure S4b). As described above, the large anion such as A1 (in Fig. 4b) showed the highest detonation velocity among anions, followed by 1nitro-N-(1-nitro-1H-tetrazol-5-yl)-N-(1-tetrazolate-5-yl)-1H-tetrazol5-amine (A2 in Fig. 4b), tetrazolate, triazolate, imidazolate, carbanion, and amine ions. Imidazolate showed the lowest detonation velocity among the azolates as did the imidazolium among the azoliums; this indicates that the charged nitrogen $\left(\mathbf{N}^{+}\right)$ in the anions of ElLs were also critical for high Dv.

Although imidazolate showed a lower $D v$ value among azolates, the $D v$ of the imidazolate group was higher than those of other small anions such as carbanion and amine anions; this was also found for the $D p$ (Fig. 4f). Therefore, it obviously shows that the number of positively influencing atoms that form the ring was important for high detonation properties, and this gives a strong premise for azole-based ElLs. Figure 5 shows the effect of combining azolium and azolate.

Specific model for azole based ions

Azole-based ionic liquids particularly attract attention as promising high energy materials with their generally high stability and
Table 3. Mean value of $D v$ and $D p$ for each ionic groups. (Bold; descriptors with the largest value in each model.)

\begin{tabular}{|c|c|c|}
\hline Cationic & $D v(\mathrm{Std})^{\mathrm{a}}$ & $D p(\mathrm{Std})^{\mathrm{a}}$ \\
\hline ammonium & $8474.4(514.6)$ & $29.6(5.8)$ \\
\hline guanidinium & $8494.1(264.5)$ & $28.2(3.2)$ \\
\hline hydrazinium & $8718.7(299.1)$ & $30.6(3.7)$ \\
\hline imidazolium & 7251.1 (746.8) & $18.6(6.5)$ \\
\hline triazolium & $8278.1(655.6)$ & $27.6(5.6)$ \\
\hline tetrazolium & $8665.1(507.2)$ & $31.1(5.8)$ \\
\hline etc. & $8021.7(649.1)$ & $25.4(6.8)$ \\
\hline Anionic & Dv & $D p$ \\
\hline amine anion ${ }^{\mathrm{b}}$ & $8250.0(785.3)$ & $28.4(6.3)$ \\
\hline carbanion & $8388.3(479.3)$ & $26.6(6.7)$ \\
\hline Oxide ion & $8764.5(449.3)$ & $29.1(4.7)$ \\
\hline imidazolate & 7848.7 (443.9) & $31.7(5.4)$ \\
\hline triazolate & $8509.5(308.3)$ & $24.2(4.1)$ \\
\hline tetrazolate & $8542.8(374.6)$ & $30.1(3.3)$ \\
\hline pyrazolate & 8477.1 (119.1) & $28.0(4.6)$ \\
\hline etc & 8124.5 (522.8) & $30.4(2.3)$ \\
\hline
\end{tabular}


high energy density. ${ }^{39,40}$ It is already established that the accuracy of the QSPR model can be increased in a structurally similar group and by narrowing the width of the data used. ${ }^{26}$ We also established an MLR-based QSPR model (QMG) for azole-based ionic liquids using the same methodology. In total, 226 data were used and 46 data were used as a training set, with the same descriptors used for QMG to afford $D v$ and $D p$ as follows.

$$
\begin{aligned}
& D v_{\text {QMGAZ }}=6215.07-6.13 \mathrm{Mw}+54.44 \mathrm{nBT}-41.02 \mathrm{nBM} \\
& -441.05 q_{t}-9.96 m O B+17.71 n R A+1849.76 C^{+} \\
& +2413.63 \mathrm{~N}^{+}-199.22 \mathrm{C}_{\mathrm{cat}}-36.16 \mathrm{H}_{\mathrm{cat}}+146.37 \mathrm{O}_{\mathrm{cat}} \\
& +106.84 \mathrm{~N}_{\text {cat }}+1160.61 \mathrm{C}^{-}+1290.88 \mathrm{~N}^{-} \\
& +1379.52 \mathrm{O}^{-}-93.24 \mathrm{C}_{\mathrm{ani}}+35.94 \mathrm{H}_{\mathrm{ani}}+71.53 \mathrm{O}_{\mathrm{ani}} \\
& +59.06 \mathrm{~N}_{\mathrm{ani}}-137.01 \mathrm{Cl}_{\mathrm{ani}} \\
& D p_{\mathrm{QMGAZ}}=18.78-0.04 \mathrm{Mw}+0.37 \mathrm{nBT}-0.35 \mathrm{nBM} \\
& -1.33 q_{t}-0.05 \mathrm{mOB}+0.07 \mathrm{nRA}+5.96 \mathrm{C}^{+}+11.8 \mathrm{~N}^{+} \\
& -1.45 \mathrm{C}_{\text {cat }}-0.55 \mathrm{H}_{\text {cat }}+2.13 \mathrm{O}_{\text {cat }}+0.78 \mathrm{~N}_{\text {cat }}+0.66 \mathrm{C}^{-} \\
& +1.83 \mathrm{~N}^{-}+3.83 \mathrm{O}^{-}-0.88 \mathrm{C}_{\mathrm{ani}}-0.32 \mathrm{H}_{\mathrm{ani}} \\
& +1.23 \mathrm{O}_{\mathrm{ani}}+0.87 \mathrm{~N}_{\mathrm{ani}}+2.08 \mathrm{Cl}_{\mathrm{ani}}
\end{aligned}
$$

The results of the MLR-based QSPR model for azole-based EILs (QMGAZ) were compared with the reference detonation properties (Fig. $5 \mathrm{a}, \mathrm{b}$ ). The correlation between the calculated Dvs by QMGAZ (Eq. 12) and reported values was much improved compared to above QMG (Eq. 7). The $\mathrm{R}^{2}, \mathrm{q}_{\mathrm{ext}}{ }^{2}$, and $\mathrm{k}$ values of the corresponding azolium models were $0.75,0.68$, and 0.75 , respectively. Furthermore, this QMGAZ model showed high $\mathrm{R}^{2}$ $(0.75), q_{\text {ext }}^{2}(0.79)$, and $k(0.74)$ for the correlation between the calculated and the reported detonation pressure (Table 1). Thus, the detonation properties of azole-based ElLs could be more accurately calculated from the QMGAZ than the QMG model. The contributions from the descriptors in QMGAZ were similar to those in QMG. For the detonation velocity, the contribution from charged atoms was increased as the number of atoms in a ring increased. The charge number (qt) tended to be inversely proportional, whereas $\mathbf{O B}$ was proportional to the detonation velocity. The higher the $\mathbf{n R A}$, the greater the detonation velocity.

Azole-based ionic liquids could be gathered into three groups depending on their composition: Azolium $\left(\mathbf{A} \mathbf{z}^{+}\right)$-Azolate $\left(\mathbf{A z}{ }^{-}\right)$, Azolium $\left(\mathbf{A z ^ { + }}\right)$-non-azolate $\left(\mathbf{N A z}{ }^{-}\right)$, and non-azolium $\left(\mathbf{N A z}{ }^{+}\right)$-Azolate $\left(\mathbf{A z}{ }^{-}\right)$, as plotted in Fig. 5c (i, ii, and iii, respectively).

Interestingly, high $D v s(D v>9,300 \mathrm{~m} / \mathrm{s})$ were observed in the asymmetric ElLs having azoliums with non-azolate $\left(\mathbf{A z}{ }^{+}-\mathbf{N A z}\right)$, or non-azolium with azolate $\left(\mathbf{N A z}^{+}-\mathbf{A z} \mathbf{z}^{-}\right.$). Meanwhile, the symmetric group $\left(\mathbf{A} \mathbf{z}^{+}-\mathbf{A} \mathbf{z}^{-}\right)$showed $D v$ distribution below $9,300 \mathrm{~m} / \mathrm{s}$ compared to the asymmetric group. It is noteworthy that the $D v$ of $\mathbf{A} \mathbf{z}^{+}-\mathbf{N A z} \mathbf{z}^{-}$pairs was largely affected by the $\mathbf{A z}{ }^{+}$structure, ranging from the lowest Dv $5,650 \mathrm{~m} / \mathrm{s}$ for imidazolium (54 in Supplementary Table S1) to the highest $9,306 \mathrm{~m} / \mathrm{s}$ for tetrazolium
(133 in Supplementary Table S1). This result agrees well with the structural analysis described above. The highest $D v$ among the azole based ILs was calculated as $9,720 \mathrm{~m} / \mathrm{s}$ for 1-nitro-N-(1-nitro$1 \mathrm{H}$-tetrazol-5-yl)-N-(1-oxide ion-tetrazol-5-yl)-1H-tetrazol-5-amine (152 in Supplementary Table S1), which is within the $\mathbf{N A z}^{+}-\mathbf{A z}$ group. Therefore, $\mathbf{A z}^{+}$and $\mathbf{A} \mathbf{z}^{-}$could be an important building block to create highly energetic ILs when combined with a $\mathbf{N A z}^{-}$ and $\mathbf{N A z}^{+}$respectively.

Furthermore, considering the contribution of the descriptors and the structures of azole ions, ILs with heterocyclic structures consist of nitrogen and oxygen atoms could be designed as a promising EIL. Thus QMG model in this work provided a positive insight to design a new ElL.

A QSPR model was established for prediction of the detonation properties for ionic liquid materials. Without the use of the heat of formation or density, a LS- or GA- based MLR model was generated using only structural descriptors. The generated QMG model showed much higher accuracy than the Kamlet-Jacobs equation that required both the density and additional computation to aid rapid design. The calculated $D v$ and $D p$ correlated to those reported in the literature with a high correlation factor $\left(R^{2}\right)$ as $R^{2}=0.71$ and 0.73 for the detonation velocity and pressure, respectively. The melting point of ElLs was also predicted by QMG. $R^{2}, q_{\text {ext }}^{2}$ and $\mathrm{k}$ values are $0.68,0.78$ and 0.66 , respectively. Among the descriptors, the contribution from the charged atoms $\left(\mathbf{C}^{+}, \mathbf{N}^{+}\right.$, $\mathbf{C}^{-}, \mathbf{N}^{-}$, and $\mathbf{O}^{-}$) was the most important in ElLs. The oxygen balance (OB) and ring forming atoms (nRA) contributed also positively to the calculated Dv. The detonation velocity and pressure of ElLs were highly dependent on both their cation and anion structure and their combination. The EILs that had small cations such as ammonium, hydroxylammonium, and hydrazinium structure showed a $D v 9,720 \mathrm{~m} / \mathrm{s}$ when combined with a large anion such as 1-nitro-N-(1-nitro-1H-tetrazol-5-yl)-N-(1-oxide iontetrazol-5-yl)-1H-tetrazol-5-amine (152). The analysis of structural QMG model was further iterated to generate a QMG model for azole-based ionic liquids with 226 azolium or azolate molecules (QMGAZ). which showed much higher accuracy (correlation $\mathrm{R}^{2}=$ 0.75 and 0.75 for $D v$ and $D p$, respectively) than QMG model based on entire 316 molecules. In particular, the QMGAZ model showed high $\mathrm{q}_{\mathrm{ext}}{ }^{2}$, and $\mathrm{k}$ values $(0.79$, and 0.74 , respectively) for the correlation of the predicted against reported detonation pressures. The contribution of the descriptors was similar to those in QMG. The $D v$ of $\mathbf{A} \mathbf{z}^{+}-\mathbf{N A z}{ }^{-}$pairs was largely affected by the $\mathbf{A} \mathbf{z}^{+}$ structure, ranging from the lowest $D v 5,650 \mathrm{~m} / \mathrm{s}$ for imidazolium (54) to the highest 9,306 m/s for tetrazolium (133). The highest $D v$ among the azole based ILs was calculated as $9,720 \mathrm{~m} / \mathrm{s}$ for tritetrazolate (152), which is within the $\mathbf{N A z}{ }^{+}-\mathbf{A z} \mathbf{z}^{-}$group. Therefore, $\mathbf{A z}^{+}$and $\mathbf{A z} \mathbf{z}^{-}$could be an important building block to create highly energetic ILs when combined with a $\mathbf{N A z}^{-}$and $\mathbf{N A z}{ }^{+}$ respectively. This provided a bright insight to design a new EIL. Considering the contribution of the descriptors and the structures of azole ions, ILs with heterocyclic structures consisting of nitrogen and oxygen atoms could be designed as a promising EIL for increasing the detonation velocity as well as pressure.

\section{METHOD}

Matlab R2017a was used for all calculations. Least mean square calculation was done by basic mldivide command with QR solver, because the number of samples is over the number of descriptors. For genetic algorithm, ga solver in optimization tool was used for calculation. The population of the genetic algorithm was 200, the crossover fraction was 0.8 , and the simulation was conducted until it reached 100,000 th generations. The source codes of each functions required to perform QSPR were written in our laboratory.

Data availability

All the data are available in supplementary information. 
(a)

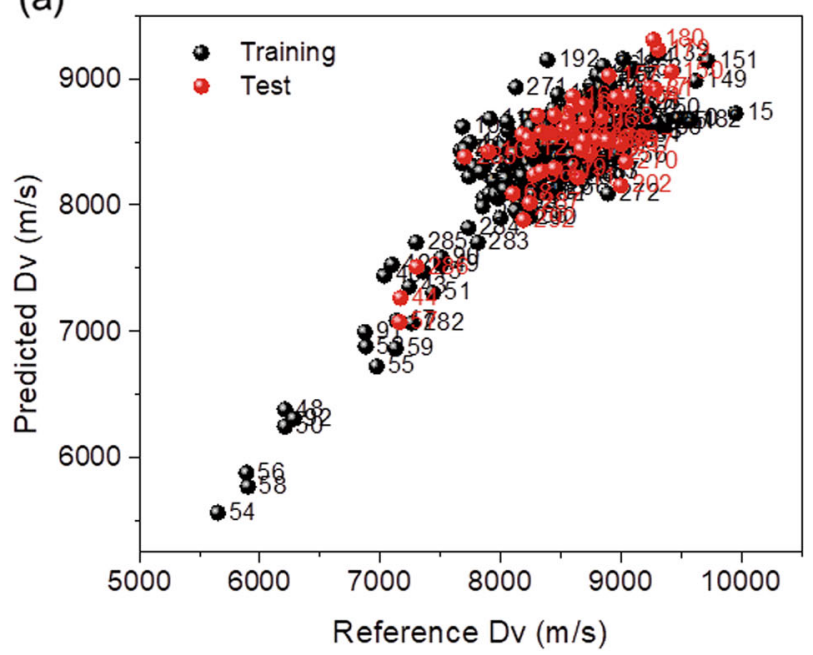

(b)

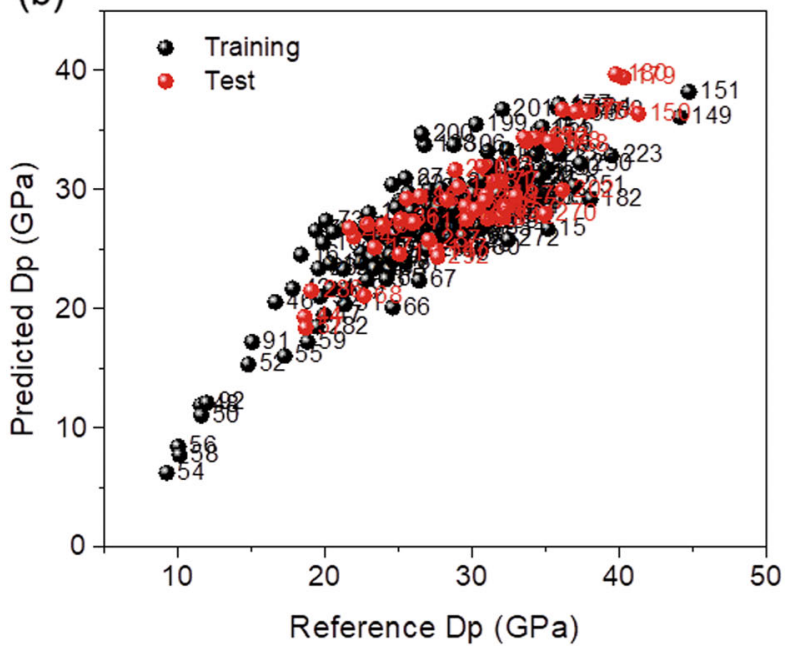

(c)

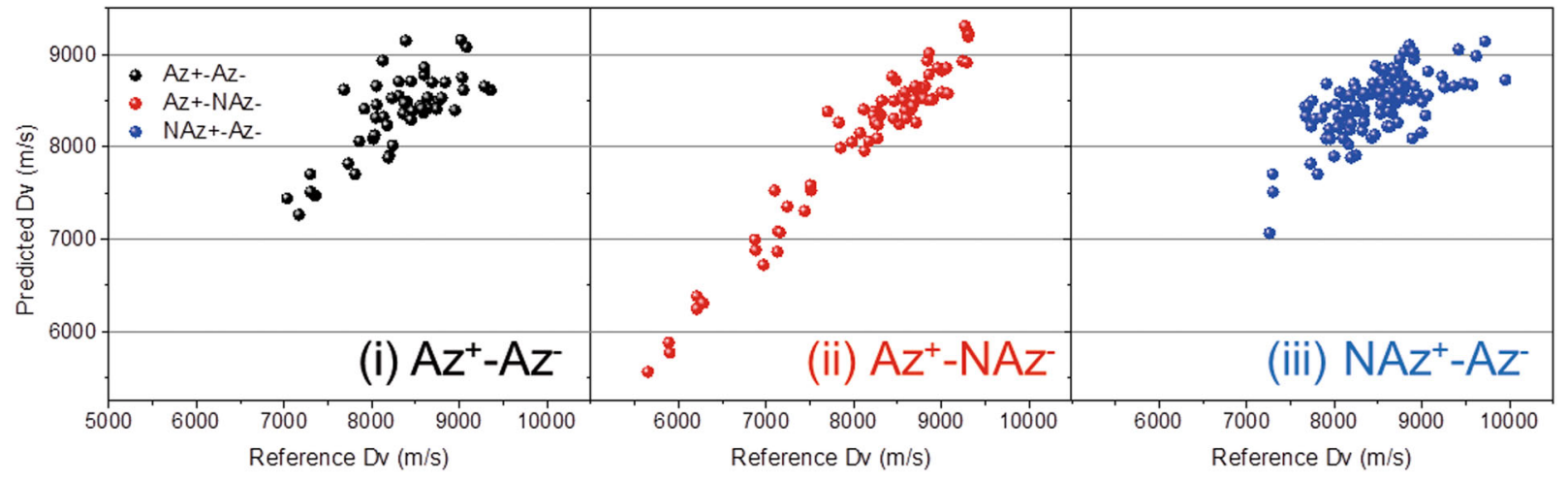

Fig. 5 Comparison of $D v(\mathbf{a})$ and $D p$ (b) between the calculated values from QMGAZ (Eq 12, 13) against literature values (c) detonation velocity, (b) detonation pressure, (c) Plot of the calculated Dvs from QMGAZ against literature for (i) Azolium $\left(A z^{+}\right)$-Azolate $\left(A z^{-}\right)$, (ii) $A z o l i u m\left(A z^{+}\right)$Non-azolate $\left(\mathrm{NAz}^{-}\right)$, and (iii) Non-azolium $\left(\mathrm{NAz}^{+}\right)$-Azolate $\left(\mathrm{Az}^{-}\right)$

\section{ACKNOWLEDGEMENTS}

This research was supported by the Next-generation Converged Energy Material Research Center (CEMRC) of the Agency for Defense Development (ADD). This research was also supported by the Global Research Laboratory (GRL) through the National Research Foundation of Korea (NRF) funded by the Ministry of Science, ICT and Future Planning (no. 2016K1A1A2912753).

\section{AUTHOR CONTRIBUTIONS}

Data collection and analysis were performed by C.P., M.H., J.K. and W.L. Calculation and analysis of results were performed by C.P. Experimental design, interpretation of the data and manuscript writing were performed by E.K.

\section{ADDITIONAL INFORMATION}

Supplementary information accompanies the paper on the npj Computational Materials website (https://doi.org/10.1038/s41524-018-0082-y).

Competing interests: The authors declare no competing interests.

Publisher's note: Springer Nature remains neutral with regard to jurisdictional claims in published maps and institutional affiliations.

\section{REFERENCES}

1. Galiński, M., Lewandowski, A. \& Stępniak, I. Ionic liquids as electrolytes. Electrochim. Acta 51, 5567-5580 (2006).
2. Lu, W. et al. Use of lonic liquids for $\pi$-conjugated polymer electrochemical devices. Science 297, 983-987 (2002).

3. Park, C. et al. Switchable silver mirrors with long memory effects. Chem. Sci. 6 , 596-602 (2015).

4. Baltazar, Q. Q., Chandawalla, J., Sawyer, K. \& Anderson, J. L. Interfacial and micellar properties of imidazolium-based monocationic and dicationic ionic liquids. Colloids Surf., A 302, 150-156 (2007).

5. Xue, H. \& Shreeve, J. M. Energetic ionic liquids from azido derivatives of 1,2,4Triazole. Adv. Mater. 17, 2142-2146 (2005).

6. Singh, R. P., Verma, R. D., Meshri, D. T. \& Shreeve, Jn. M. Energetic nitrogen-rich salts and ionic liquids. Angew. Chem., Int Ed. 45, 3584-3601 (2006).

7. Wishart, J. F. Energy applications of ionic liquids. Energy Environ. Sci. 2, 956-961 (2009).

8. Jones, C. B., Haiges, R., Schroer, T. \& Christe, K. O. Oxygen-balanced energetic ionic liquid. Angew. Chem. 118, 5103-5106 (2006).

9. $\mathrm{Xu}, \mathrm{J}$.-G. et al. Nitrogen-rich tetranuclear metal complex as a new structural motif for energetic materials. ACS Omega 2, 346-352 (2017).

10. Schneider, S. et al. lonic liquids as hypergolic fuels. Energy Fuels. 22, 2871-2872 (2008).

11. Zhang, Q. \& Shreeve, Jn. M. Energetic ionic liquids as explosives and propellant fuels: a new journey of ionic liquid chemistry. Chem. Rev. 114, 10527-10574 (2014).

12. Le Bideau, J., Viau, L. \& Vioux, A. lonogels, ionic liquid based hybrid materials. Chem. Soc. Rev. 40, 907-925 (2011).

13. Zhang, Y. \& Shreeve, Jn. M. Dicyanoborate-based ionic liquids as hypergolic fluids. Angew. Chem., Int Ed. 50, 935-937 (2011).

14. Huang, S., Qi, X., Zhang, W., Liu, T. \& Zhang, Q. Exploring sustainable rocket fuels: [imidazolyl-amine-BH2]+-cation-based ionic liquids as replacements for toxic hydrazine derivatives. Chem. - Asian J. 10, 2725-2732 (2015). 
15. Zeng, X., Miao, C., Wang, S., Xia, C. \& Sun, W. Asymmetric 5-endo chloroetherification of homoallylic alcohols toward the synthesis of chiral [small beta]chlorotetrahydrofurans. Chem. Commun. 49, 2418-2420 (2013).

16. Huang, H., Shi, Y., Liu, Y. \& Yang, J. 1,2,4,5-Dioxadiazine-functionalized [N-NO2]furazan energetic salts. Dalton. Trans. 45, 15382-15389 (2016).

17. Ye, C., Gao, H., Twamley, B. \& Shreeve, Jn. M. Dense energetic salts of N,N[prime or minute]-dinitrourea (DNU). New J. Chem. 32, 317-322 (2008).

18. Thottempudi, V. \& Shreeve, Jn. M. Synthesis and promising properties of a new family of high-density energetic salts of 5-nitro-3-trinitromethyl-1H-1,2,4-triazole and 5,5'-bis(trinitromethyl)-3,3'-azo-1H-1,2,4-triazole. J. Am. Chem. Soc. 133, 19982-19992 (2011).

19. Kamlet, M. J. \& Jacobs, S. J. Chemistry of detonations. i. a simple method for calculating detonation properties of $\mathrm{C}-\mathrm{H}-\mathrm{N}-\mathrm{O}$ explosives. J. Chem. Phys. 48, 23-35 (1968).

20. Sućeska, M. Calculation of detonation parameters by EXPLO5 computer program. Mater. Sci. Forum 465-466, 325-330 (2004).

21. Fried, L CHEETAH: A Fast Thermochemical Code For Detonation (Lawrence Livermore National Lab, CA, USA, 1993).

22. Katritzky, A. R. et al. Quantitative correlation of physical and chemical properties with chemical structure: utility for prediction. Chem. Rev. 110, 5714-5789 (2010).

23. Ghanem, O. B. et al. Effect of imidazolium-based ionic liquids on bacterial growth inhibition investigated via experimental and QSAR modelling studies. J. Hazard. Mater. 297, 198-206 (2015).

24. Zhao, X. et al. Thermal hazard of ionic liquids: modeling thermal decomposition temperatures of imidazolium ionic liquids via QSPR method. Ind. Eng. Chem. Res. 56, 4185-4195 (2017)

25. Karelson, M., Lobanov, V. S. \& Katritzky, A. R. Quantum-chemical descriptors in QSAR/QSPR studies. Chem. Rev. 96, 1027-1044 (1996).

26. Tropsha, A., Gramatica, P. \& Gombar, V. K. The importance of being earnest: validation is the absolute essential for successful application and interpretation of QSPR models. Qsar. Comb. Sci. 22, 69-77 (2003).

27. Balfagón, A. C., Serrano-Hernanz, A., Teixido, J. \& Tejedor-Estrada, R. Comparative study of neural networks and least mean square algorithm applied to the optimization of cosmetic formulations. Int. J. Cosmet. Sci. 32, 376-386 (2010).

28. Holland, J. H. Adaptation in Natural And Artificial Systems. An Introductory Analysis With Application To Biology, Control, And Artificial Intelligence. (University of Michigan Press, Ann Arbor, Ml, 1975).

29. Tochigi, K. \& Yamamoto, H. Estimation of ionic conductivity and viscosity of ionic liquids using a QSPR model. J. Phys. Chem. C. 111, 15989-15994 (2007).

30. Worth, A. P., Van Leeuwen, C. J. \& Hartung, T. The prospects for using (Q)SARs in a changing political environment--high expectations and a key role for the european commission's joint research centre. SAR. Qsar. Environ. Res. 15, 331-343 (2004).
31. Jaworska, J., Nikolova-Jeliazkova, N. \& Aldenberg, T. QSAR applicability domain estimation by projection of the training set descriptor space: a review. ATLA 33, 445 (2005).

32. Roy, K., Kar, S. \& Ambure, P. On a simple approach for determining applicability domain of QSAR models. Chemom. Intell. Lab Syst. 145, 22-29 (2015).

33. Ghule, V. D., Deswal, S., Devi, A. \& Kumar, T. R. Computer-aided design of energetic tris (tetrazolyl) amine derivatives and salts. Ind. Eng. Chem. Res. 55, 875-881 (2016).

34. Strachan, A., Kober, E. M., Duin, A. C. Tv \& Oxgaard, J. III, WAG. Thermal decomposition of RDX from reactive molecular dynamics. J. Chem. Phys. 122, 054502 (2005).

35. Stine, J. R. On predicting properties of explosives - detonation velocity. J. Energ. Mater. 8, 41-73 (1990).

36. Keshavarz, M. H. \& Pouretedal, H. R. Predicting the detonation velocity of CHNO explosives by a simple method. Propellants, Explos., Pyrotech. 30, 105-108 (2005).

37. Tang, Y., He, C., Mitchell, L. A., Parrish, D. A. \& Shreeve, Jn. M. Small cation-based high-performance energetic nitraminofurazanates. Chem. - A Eur. J. 22, 11846-11853 (2016)

38. Kuchurov, I. V., Zharkov, M. N., Fershtat, L. L., Makhova, N. N. \& Zlotin, S. G. Prospective symbiosis of green chemistry and energetic materials. ChemSusChem 10, 3914-3946 (2017).

39. Xue, H., Gao, Y., Twamley, B. \& Shreeve, Jn. M. Energetic azolium azolate salts. Inorg. Chem. 44, 5068-5072 (2005).

40. Gao, Y., Gao, H., Piekarski, C. \& Shreeve, Jn. M. Azolium salts functionalized with cyanomethyl, vinyl, or propargyl substituents and dicyanamide, dinitramide, perchlorate and nitrate anions. Eur. J. Inorg. Chem. 2007, 4965-4972 (2007).

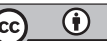

Open Access This article is licensed under a Creative Commons Attribution 4.0 International License, which permits use, sharing, adaptation, distribution and reproduction in any medium or format, as long as you give appropriate credit to the original author(s) and the source, provide a link to the Creative Commons license, and indicate if changes were made. The images or other third party material in this article are included in the article's Creative Commons license, unless indicated otherwise in a credit line to the material. If material is not included in the article's Creative Commons license and your intended use is not permitted by statutory regulation or exceeds the permitted use, you will need to obtain permission directly from the copyright holder. To view a copy of this license, visit http://creativecommons. org/licenses/by/4.0/.

(c) The Author(s) 2018 